\title{
Suppressive Effect of Aspirin on Chromosome Aberration Induced by Mitomycin C in Mice
}

\author{
Miki NiIKAWA, ${ }^{a}$ Takeshi NAKAmURA, ${ }^{b}$ and Hisamitsu NAGASE ${ }^{*}, b$ \\ Ichinomiya Women's Junior College, ${ }^{a} 6$ Nikkou-cho, Ichinomiya 491-0938, Japan and Gifu Pharmaceutical University, ${ }^{b}$ \\ 5-6-1 Mitahora-higashi, Gifu 502-8585, Japan. Received December 21, 2000; accepted April 16, 2001
}

\begin{abstract}
Chromosome aberrations induced by mitomycin C (MMC) were suppressed by aspirin in a mouse micronucleus test with peripheral blood and bone marrow cells. Aspirin at doses of $0.5,5$, and $50 \mathrm{mg} / \mathrm{kg}$ was injected intraperitoneally or per administered orally $0.5,6$, or $24 \mathrm{~h}$ after administration of MMC and then peripheral blood and/or bone marrow cells were sampled $48 \mathrm{~h}$ after administration of MMC. The suppressive effect of aspirin was more pronounced in the aspirin-treated groups $24 \mathrm{~h}$ than 0.5 and $6 \mathrm{~h}$ after administration of MMC. In the aspirin-treated group at $24 \mathrm{~h}$, the frequency of polychromatic erythrocytes with micronuclei was decreased by about $60-80 \%$ after intraperitoneal injection and by about $40-70 \%$ after oral administration. It is suggested that aspirin may directly act on MMC metabolites, but not on MMC itself.
\end{abstract}

Key words aspirin; mitomycin C; micronucleus test

Recently, there have been many reports that anticancer agents that have mutagenic ${ }^{1-4)}$ and/or carcinogenic ${ }^{5-7)}$ characteristics generate secondary cancers, and this has become a serious problem. Nonsteroidal antiinflammatory drugs (NSAIDs) are sometimes used to relieve the pain of patients undergoing cancer treatment.

Aspirin inhibited bladder carcinogenesis induced by $\mathrm{N}$-[4(5-nitro-2-furyl)-2-thiazolyl] formamide (FANFT) ${ }^{8,9)}$ In animal model studies, daily subcutaneous injections of aspirin for 1 week before and after carcinogen administration inhibited 1,2-dimethylhydrazine-induced colon carcinogensis, whereas it had no effect when administered for 4 weeks after the carcinogen treatment. ${ }^{10)}$ Colon cancer induced by azoxymethane in F344 rats was inhibited by the chemopreventive properties of dietary aspirin at different dose levels. ${ }^{11)}$ Furthermore, epidemiological studies have revealed that the use of aspirin might reduce the risk of development of colon cancer and mortality. ${ }^{12-14)}$

We attempted to elucidate why aspirin acts as a cancer preventive agent. As a clastogen, we used mitomycin C (MMC), which is widely used in cancer treatment as a potent anticancer agent with an antibacterial spectrum. In this study, we investigated the anticlastogenic potential of aspirin using a mouse micronucleus test.

\section{MATERIALS AND METHODS}

Animals Seven-week-old male ICR mice were purchased from SLC (Shizuoka, Japan) and used for the experiments at the age of 8 weeks. Each group in the micronucleus test consisted of three animals.

Chemicals MMC (CAS No. 50-07-2) was purchased from Kyowa Hakko (Tokyo, Japan) and aspirin (CAS No. 5078-2) was purchased from Nacalai Tesque Co., Ltd. (Tokyo, Japan). MMC was dissolved in distilled water. Aspirin was suspended in $10 \%$ arabic gum solution.

Animal Treatment and Micronucleus Test Treatment: MMC was administered once to the mice at a dose of 1 $\mathrm{mg} / \mathrm{kg}$ by intraperitoneal injection. Aspirin was administered at doses of $0.5,5$, and $50 \mathrm{mg} / \mathrm{kg}$. Aspirin was injected intraperitoneally or given orally $0.5,6$, or $24 \mathrm{~h}$ after administration of MMC.
When aspirin was given to mice $24 \mathrm{~h}$ after administration of MMC, bone marrow cells and peripheral blood were sampled $48 \mathrm{~h}$ after administration of MMC. When aspirin was given to mice 0.5 and $6 \mathrm{~h}$ after administration of MMC, only peripheral blood was sampled $48 \mathrm{~h}$ after administration of MMC.

Micronucleus Test The micronucleus test was carried out using the procedure of Hayashi et al. ${ }^{15)}$ The frequencies of polychromatic erythrocytes with micronuclei (MNPCEs) per 1000 polychromatic erythrocytes (PCEs) and peripheral reticulocytes with micronuclei (MNRETs) per 1000 peripheral reticulocytes (RETs) were determined. Statistical significance was evaluated using Student's $t$-test.

Biochemical Assay Peripheral blood was obtained from the tail vein and the hematocrit tube was centrifuged at $12000 \mathrm{~g}$ for $5 \mathrm{~min}$. Then the volume percentage of red cells was determined.

The experimental animals were killed $48 \mathrm{~h}$ after administration of MMC. Capiject ${ }^{\circledR}$ (Terumo Co., Ltd., Tokyo, Japan) was used to collect a blood sample from the heart, which was centrifuged at $9000 \boldsymbol{g}$ for $30 \mathrm{~min}$ to obtain the plasma. GOT and GPT were analyzed using a SPOTCHEM SP-4420 (Kyoto Daiichi Kagaku Co., Ltd., Kyoto, Japan).

\section{RESULTS}

Micronucleus Test The clastogenicity of aspirin was measured by the micronucleus test, and aspirin at a doses of $0.5,5$, and $50 \mathrm{mg} / \mathrm{kg}$ was administered intraperitoneally or orally $0.5,6$, or $24 \mathrm{~h}$ after administration of distilled water instead of MMC as a negative control. No clastogenicity of aspirin was observed (data not shown).

The effects of aspirin injected intraperitoneally or given orally after administration of MMC were investigated at different times. The results are shown in Table 1. No suppressive effect of aspirin was observed $0.5 \mathrm{~h}$ after intraperitoneal or oral administration or $6 \mathrm{~h}$ after intraperitoneal administration after administration of MMC. When aspirin was given at doses of 0.5 and $50 \mathrm{mg} / \mathrm{kg} 6 \mathrm{~h}$ after the oral MMC, micronucleus induction by MMC was suppressed by 37 and $38 \%$, respectively. The frequency of MNRETs was decreased by 55 , 43 , and $45 \%$ after intraperitoneal aspirin and by 34,42 , and 
Table 1. Effect of Aspirin Administration on Frequency of MMC-Induced MNRETs

\begin{tabular}{|c|c|c|c|c|c|c|c|}
\hline \multirow{3}{*}{$\begin{array}{l}\mathrm{MMC} \\
(\mathrm{mg} / \mathrm{kg})\end{array}$} & \multirow{3}{*}{$\begin{array}{l}\text { Aspirin } \\
(\mathrm{mg} / \mathrm{kg})\end{array}$} & \multicolumn{6}{|c|}{ Frequency of MNRETs } \\
\hline & & \multicolumn{2}{|c|}{$\begin{array}{c}0.5 \mathrm{~h} \\
\text { Mean土S.D. (\%) }\end{array}$} & \multicolumn{2}{|c|}{$\begin{array}{c}6 \mathrm{~h} \\
\text { Mean } \pm \text { S.D. }(\%)\end{array}$} & \multicolumn{2}{|c|}{$\begin{array}{c}24 \mathrm{~h} \\
\text { Mean } \pm \text { S.D. }(\%)\end{array}$} \\
\hline & & i.p. & p.o. & i.p. & p.o. & i.p. & p.o. \\
\hline 0 & 0 & $0.21 \pm 0.1$ & $0.13 \pm 0.1$ & $0.13 \pm 0.1$ & $0.26 \pm 0.2$ & $0.23 \pm 1.1$ & $0.14 \pm 0.1$ \\
\hline 1 & 0 & $3.43 \pm 1.0$ & $3.59 \pm 0.8$ & $3.13 \pm 0.8$ & $4.36 \pm 0.7$ & $4.49 \pm 0.6$ & $3.75 \pm 1.0$ \\
\hline 1 & 0.5 & $2.78 \pm 1.4$ & $3.44 \pm 0.4$ & $2.71 \pm 0.7$ & $2.75 \pm 1.0 * * *$ & $2.01 \pm 1.2 * * *$ & $2.48 \pm 0.5^{* *}$ \\
\hline 1 & 5 & $2.97 \pm 0.7 * *$ & $3.00 \pm 0.7$ & $3.38 \pm 1.0$ & $3.63 \pm 0.6^{*}$ & $2.57 \pm 0.8 * * *$ & $2.18 \pm 0.9 * * *$ \\
\hline 1 & 50 & $3.26 \pm 0.2 * *$ & $3.78 \pm 1.2$ & $2.58 \pm 0.8$ & $2.69 \pm 0.8 * * *$ & $2.48 \pm 1.1 * * *$ & $2.76 \pm 1.1 *$ \\
\hline
\end{tabular}

Significant decrease: $* p<0.05 ; * * p<0.01 ; * * * p<0.001$.

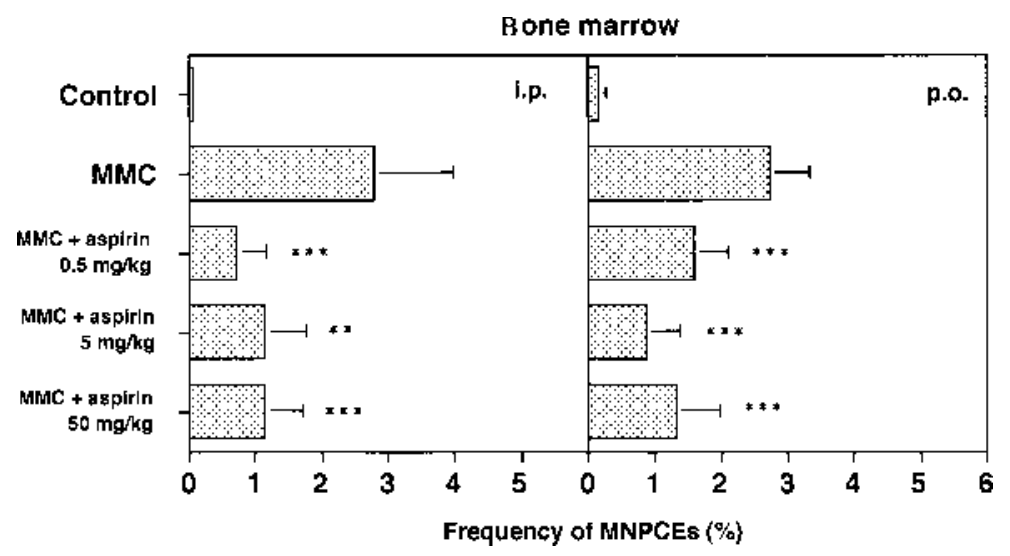

Fig. 1. Effect of Aspirin Administration on Frequency of MMC-Induced MNPCEs (24h after Administration of MMC)

Error bars indicate the standard error of mean values. MNPCEs in aspirin- and MMC-treated mice were compared with those in mice that received MMC alone. Student's $t$-test was used for statistical analysis, and $p$ values, $<0.05(*),<0.01(* *)$ and $<0.001(* * *)$ were considered statistically significant.

$26 \%$ by after oral aspirin $0.5,5$, and $50 \mathrm{mg} / \mathrm{kg} 24 \mathrm{~h}$ after administration of MMC. The suppressive effect of aspirin on MMC-induced MNRETs was not dose dependent.

The MNPCE frequencies in the intraperitoneal or oral aspirin-treated groups $24 \mathrm{~h}$ after administration of MMC are shown in Fig. 1. The frequency of MNPCEs was decreased by 84,59 , and $59 \%$ after intraperitoneal and by 42,68 , and $51 \%$ after oral aspirin at doses of $0.5,5$, and $50 \mathrm{mg} / \mathrm{kg}$ at $24 \mathrm{~h}$.

Biochemical Assay GOT and GPT values in the blood samples of all animals used for the experiments, were determined, and all were in the normal range (data not shown).

\section{DISCUSSION}

Micronucleus induction of MNRETs and MNPCEs by MMC was significantly decreased by intraperitoneal or oral administration of aspirin $24 \mathrm{~h}$ after the administration of MMC. However, it is not clear whether that suppression is dose dependent.

Antimutagens are classified into two groups: desmutagens and bioantimutagens. Desmutagens act directly on mutagens to decrease their mutagenicity and may decrease the effectiveness of anticancer drugs. Bioantimutagens interfere with cellular functions that convert primary DNA damage into gene mutations and may prevent carcinogenesis by mutagenic anticancer agents without decreasing their medialefficacy. ${ }^{16)}$ In a previous paper, ${ }^{17)}$ we reported the bioantimuta- genic effect of aspirin on the MMC-induced somatic mutation and recombination test (SMART) in Drosophila melanogaster. The present results, confirmed that aspirin has bioantimutagenicity and suppresses $\mathrm{MMC}$-induced chromosomal aberrations in mice. MMC is a broad-spectrum antibiotic and also has been used as an anticancer agent in the treatment stomach, lung, and colon cancers. Aspirin is an NSAID often given to cancer patients for pain relief. It has been suggested that aspirin can prevent the occurrence of secondary cancer caused by mutagenic anticancer agent.

Mozdarani et al. ${ }^{18)}$ reported that cimetidine reduced the clastogenic effect of X-rays. The mechanism by which cimetidine reduces the clastogenic effect of neutrons is not fully understood. Lapenna et al. ${ }^{19)}$ have shown that $\mathrm{H}_{2}$ receptor antagonists such as cimetidine can scavenge hydroxy radicals.

NADPH cytochrome P-450 reductase can generate oxygen radicals, specifically, superoxide radicals from MMC. ${ }^{20)}$ The superoxide radicals generated by MMC may be mutagenic. ${ }^{21)}$ Other studies showed aspirin has hydroxy radical scavenging ability. ${ }^{223)}$ In this study, aspirin inhibited the chromosomal aberrations induced by MMC. However, we have not clarified the antimutagenic mechanism by which aspirin decreases the frequency of MNPCEs and MNRETs induced by MMC.

When aspirin was given to mice $24 \mathrm{~h}$ before the administration of MMC, no reduction in the frequency of MNRETs was observed. Based on this result, aspirin may directly act on MMC metabolites, but not on the MMC itself. Aspirin is rapidly hydrolyzed to salicylic acid, and salicylic acid is fur- 
ther metabolized in the liver and kidneys. More intensive research is required to determine whether the radical scavenging activity of aspirin metabolites are associated with its mechanism of suppression of MMC-induced chromosomal aberrations.

\section{REFERENCES}

1) Banerjee A., Benedict W. F., Cancer Res., 39, 797-799 (1979).

2) Singh B., Gupt R. S., Cancer Res., 43, 577-584 (1983).

3) Pedersen-Bjergaard J., Janssen J. W. G., Lyons J., Philip P., Bartram C. R., Cancer Res., 48, 1812-1817 (1988).

4) Rossi C., Poli P., Candi A., Buschini A., Mutation Res., 390, 113-120 (1997).

5) Marselos M., Vainio H., Carcinogenesis, 12, 1751-1766 (1991).

6) Dedrick R., Morrison P. F., Cancer Res., 52, 2464-2467 (1992).

7) Sanderson B. J., Ferguson L. R., Denny W. A., Mutation Res., 355, 59-70 (1996).

8) Cohen S. M., Zenser T. V., Murasaki G., Fukushima S., Mattammal M. B., Rapp N. S., Davis B. B., Cancer Res., 41, 3355-3359 (1981).

9) Murasaki G., Zense T. V., Davis B. B., Cohen S. M., Carcinogenesis, 5, 53-55 (1984).

10) Craven A., DeRubertis F. R., Carcinogensis, 131, 541—546 (1992).

11) Reddy B. S., Rao C. V., Rivenson A., Kelloff G., Carcinogensis, 14,
$1493-1497$ (1993).

12) Thun M. J., Namboodiri M. M., Heath C. W., Jr., N. Engl. J. Med., 325, $1593-1596$ (1991).

13) Thun J. M., Namboodiri M. M., Calle E. E., Flanders W. D., Heath C. W., Jr., Cancer Res., 53, 1322-1327 (1993).

14) Kune G. A., Kune S., Watson L. F., Cancer Res., 48, 4399-4404 (1988).

15) Hayashi M., Morita T., Kodama Y., Sofuni T., Ishidade M., Jr., Mutation Res., 245, 245-249 (1990).

16) Kada T., Inoue T., Ohta T., Shirasu Y., "Antimutagenesis and Anticarcinogenesis Mechanism; Basic Life Science," Vol. 39, ed. by Shankel D. M., Hartman P. E., Kada T., Hollaender A., Plenum, New York, 1986, pp. $181-196$.

17) Sato T., Nagaoka K., Nagase H., Niikawa M., Kito H., Jpn. J. Toxicol. Environ. Health, 42, 136-141 (1996).

18) Mozdarani H., Khoshibin-Khoshnazar A. R., Cancer Lett., 124, 6571 (1998).

19) Lapenna D., Degioia S., Mezetti A., Grossi L., Festi D., Marzio F., Coccurullo F., Eur. J. Clin. Invest., 24, 476-481 (1994).

20) Bligh H. F. J., Bartoszek A., Robson C. N., Hickson I. D., Kasper C. B., Beggs J. D., Wolf C. R., Cancer Res., 50, 7789-7792 (1990).

21) Dillard C. J., Tappel A. L., Free Radical Biol. Med., 7, 193-196 (1989).

22) Aruoma O. I., Halliwell B., Xenobiotica, 18, 459-470 (1988).

23) Oyanagui Y., Biochem. Pharmacol., 25, 1473-1480 (1976). 